\title{
A Study on the Synergistic Development of Instrumental and Humanistic Strategies in College English Curriculum
}

\author{
Guangcai Li \\ Jilin Agricultural University, Changchun, China \\ 372415102@qq.com
}

Keywords: Synergistic development; Instrumental; Humanity; College English curriculum

\begin{abstract}
Based on the teaching philosophy of foreign language, this paper aims to establish the way of college English school-based teaching goal of instrumental and humanistic characteristic in local colleges and universities according to the rules of language teaching, social needs and students' individual learning needs. In order to construct three-dimensional, open, Multi-level college English school-based curriculum system, the paper is designed to provide guidance to the next step in college English teaching reform in a comprehensive and effective manner.
\end{abstract}

\section{Introduction}

As an organic part of higher education, and a compulsory basic course, College English is not only a basic course of language knowledge, but also broadens the knowledge and understanding of the world culture in quality education courses. College English teaching is based on dialogue, communication, understanding and cooperation with the guidance of foreign language teaching theory. English, the carrier of culture, is represented as the English language knowledge and application skills, cross-cultural communication and learning strategies between teachers and students, among which its main content is language knowledge, skills and cultural heritage and creation of special exchanges. According to the "College English Teaching Guide", we must change the concept of education and teaching, innovate teaching content and curriculum system, reform teaching methods and teaching methods, improve the test evaluation system for college students to create a three-dimensional, diversified, personalized learning environment and atmosphere. Its main ideal goal is to improve the quality of college English teaching, to meet national and social needs of personnel training in face of the challenge from the new era full of competition.

\section{The Concept of the Humanity and Instrumental}

"Humanity" and "instrumental" are the basic concepts that people often use when discussing foreign language education. The former is embodied in the value level, and the latter is the methods and means used to realize this value. The conflict between the two has a long history; it is focused that which is in the leading position during the development of foreign language education. There is no doubt that English courses with the characteristic of instrumental and humanistic are conducive to laying the foundation for the lifelong development of students. But in reality, the two are often fragmented, and can not be taken into account. In the context of globalization, English teaching should not only meet the needs of international education and extend a large number of international visions, but also master international rules and participate in international affairs and competition of international talents so as to prepare the students for the future and lifelong learning need. Therefore, it is an inevitable trend that the organic unity of instrumental and humanistic in college English classroom is better to be realized in the development of English education in China.

"Instrumental" refers to the instruments used in the work, and then extended to a means of teaching "how to achieve, complete or promote a thing". Language is used to exchange information, carry culture and disseminate knowledge as a most important tool. College English serves as a tool to impart knowledge, spread culture and cultivate communicative competence. The teaching of "instrumental" is reflected in: (1) teaching English language knowledge and this knowledge can 
enable us to have the ability to communicate with people in foreign countries. This ability is that we communicate with people with the tools; (2) the spreading Chinese and Western cultures. College English teaching can make us understand more advanced cultures of Westerners and of our own, and spread our long-established culture to the rest of the world. Therefore, college English teaching is an important way to promote cultural exchange between Chinese and western cultures and enhance cultural literacy. (3) Developing ability of the students who are ready to accept the traditional or up-to-date cultures. The purpose of College English teaching is not only to impart knowledge and culture. From the functional point of view, each course can promote the development of students' ability. In addition, college English teaching can also promote the students' development of their own. On the basis of the study in neurophysiology, speech psychology psycholinguistics, the findings have revealed that if people only learn the mother tongue, the result lies in the main use and development of the left hemisphere of the brain, but if you learn foreign language, the brain will be the right hemisphere to start and develop. As a result, the English language learning will inevitably contribute to the development of the human brain, and develop their abilities to deal with different issues.

The fundamental idea of "humanity is to think about the human beings from the perspective of human beings, and to think about the various social relations of people as the center, that is, to care for people, especially the spiritual life of people. Man can exist in particular respect for the value of man as a spiritual existence. From the standpoint of college English teaching, "humanity" is not only to highlight the harmonious development of students' physical and mental health in the process of teaching, but also to highlight the respect, recognition and attention of the individual life, human rights and value of students individual as the main body as the starting point of school teaching. Selection is conducive to cultivating students to question the spirit of training their personality teaching content, and actively play the students' initiative, emphasizing the students as the main initiative to participate in teaching activities to promote heuristic teaching. In order to realize the goal of synergize the characteristics of instrumental and humanity in the process of teaching language, efforts should be made to find individual differences among students to cultivate students' humanistic spirit and quality and instrumental motivation.

\section{The Collaborative Development of the Two Concepts in Teaching English}

College English education should reflect the dual purpose-one is to embody the utterance in the ultimate goal and the other is to embody the humanity in the education and teaching process, so the organic unity is instrumental and humanity in college English curriculum orientation. To promote the general education or "foreign language" and to build "three sets of car"-teaching mode, the English language, Chinese and foreign culture and multidisciplinary knowledge-systematically into the teaching, the college English curriculum should be poured into English language learning and skills training, Cross-cultural communication and through English to obtain a multidisciplinary knowledge of a comprehensive, multi-functional courses to improve the level of personnel training.

English education and relevant authorities should establish a new understanding that English education is not only a technical education, but also the function of humanity education, as an important part of quality education, focuses on skills training curriculum system drawbacks which lies in its overall emphasis on language skills training, ignoring the consistency of knowledge to absorb, the lack of humanistic knowledge of the connotation and depth, is not conducive to systematically cultivating students' ability to judge and speculate. Its starting point is to need to start from the purpose of education, curriculum system, teacher training, and assessment methods and so on. Curriculum design can not be limited to imparting language knowledge and training skills, to set up a wide range of teaching objectives, to provide students with independent development time and space. 


\section{The Instrumental and Humanity Curriculum under the Orientation of College English Curriculum}

In order to fully embody the instrumental and humanistic nature of English teaching, the college English curriculum should be a diversified curriculum system based on differences and flexibility. It should be combined with compulsory and elective courses. School setting should be based on both language skills courses and humanistic common education courses, Input and output capacity training courses, ESP and EAP courses.

Compulsory and Elective combination. Compulsory courses can help students strengthen basic language skills. Elective courses (including language skills development courses, cultural general courses, ESP courses, EAP courses, EOP courses, etc.) can expand students' international perspectives and help them become familiar with international rules. If you start a basic English course in the first year (the teacher is mainly concerned with general English), different types of outreach programs are offered for students from the second academic year according to the actual situation of the students (including students' professional interests, interests, English level, etc.) Do both the basis of both students, but also expand the students' professional development space and international perspective. With a part of the time to strengthen the language skills of most students, they necessarily have the basic quality of qualified college students, and for learning to spare capacity, they want to learn English in this professional knowledge, in order to meet students' need of taking up a variety of elective courses to a certain extent.

Courses for Language Skills and General Courses for Humanity Spirit. The Humanities Liberal Studies course refers to those courses in English that are related to English-speaking countries' cultural practices, as well as a number of general courses related to liberal arts courses (science and engineering courses because of its too strong professional and lack of college English teachers to teach feasible Sex). These courses can systematically introduce the rules and practices of people in other countries, such as culture, customs, or some common rules in foreign relations, which can broaden the international view of students and gradually become familiar with the objectives of international rules. This is especially important in general universities, because undergraduates in such schools are mainly engaged in practical work in the future, not in international academic exchanges or high-end research work. As for the academic research university, because of its high quality students and students after graduation job search (or further study) different orientation can be appropriate to increase ESP. It is also possible to alleviate the worries of public English teachers' layoffs and explore ways to improve the quality of the course. These courses provide teachers with a scientific research platform for the development of teachers and students in order to produce a win-win effect.

Courses for Training the Input and Output Capacity. Language learning is a process from input to output, both of which are indispensable. For a long time, owing to many factors such as the class size, teaching philosophy and teaching conditions and the like, college English courses put more emphasis on input, especially reading input, at the same time ignore the process of output. Since 2002, the Ministry of Education has initiated the reform of college English teaching, which emphasizes the ability to improve students' listening and speaking. Since then, many schools have transformed the courses for improving reading and listening ability into both courses which combine reading and listening. Many courses were separately designed like separate oral courses, and oral exams were added in the academic examinations. On the last round of teaching reform for more than a decade, many colleges and universities take a series of measures (such as the establishment of network autonomous learning room, open oral classes, oral examinations, etc.) in the expectation of cultivating students' ability to output language, but many students still reflect that the spoken ability is the ability they are eager to improve. Therefore, a new round of teaching reform should continue to attach importance to language input at the same time to create opportunities for students to pour out more language in the classroom or on other occasions, mainly to cultivate and enhance their oral and written expression.

ESP and EAP Courses Based on School Settings. When planning courses such as ESP and EAP, you should take full account of the school level and the student's professional competence and 
interest. Otherwise, the training objectives of these courses will still be unavoidable and will ultimately waste the valuable time of students who do not need such courses. ESP and EAP courses are not appropriate for all college English teachers because of different competences in language teaching, which is mainly caused by the limitations of English teachers with professional knowledge structure.

\section{Building the Curriculum System with the Instrumental and Cultural Dual Attributes}

Instrumental and Cultural Unity in College English Courses. The college English curriculum has rich cultural connotations, which can cultivate students' rational knowledge and humanistic spirit of the world, nation and society and life, and develop students' autonomous learning ability and extend their international visions, and ultimately improve the comprehensive quality of students. At the same time, the college English curriculum system can become working language in English and social oral and written communicative tools to meet the needs of development in students' career and social life.

Combination of Basic and Applied Nature of the Course. For many years, many colleges and universities lay more emphasis on the teaching on the basic language knowledge and look down upon its applied nature of the language. In order to change the picture of lack of appliance in English atmosphere, the authorities concerned should better provide a variety of options to meet the students' individual needs at the stage of undergraduate professional learning, in the expectation of applying their language knowledge and skills to tackle a variety of tough problems in the years to come when they leave school for real life in the real world in terms of job and personal interests and development and other needs.

Differences and Relevance Reflected in College English Curriculum Different schools at different levels should be built in line with our school students and school orientation of the curriculum system, within the same school, for different professional and personality needs, students with different basic language knowledge should be provided appropriate multi-level personalized curriculum system. Colleges and universities should take effective measures to face the now challenge in the reform of language teaching. Previously our schools supply one-size teaching approach to teach students with respect to the need of different individuals among students. With time going, students' awareness of being independent of learning was aroused because of social rapid development. As a result, it is urgent for the higher learning institutions to carry out more policies to cater for the diverse tastes from various perspectives.

College English Courses with Service Value. As an important public basic course, College English can serve as a vital tool to attain the school's goal of providing more dishes for the students in our class. One is to serve the professional needs of the faculty, with the other serving the needs of students' personality development, especially in the process of educational internationalization, which plays an important role.

\section{Conclusion}

The goal of college English teaching should be multi-level and diversified. Accordingly the design concepts should be adapted to the real situation of colleges and universities and society. On the basis of documents, teachers and students should provide more chances to fulfill the needs of students and individuals, and provide schools, teachers and students with larger choices and development space which can become a student favorite and benefit a lifelong course. Therefore, the design of college English curriculum should be based on the combination of instrumental and humanistic principles. According to the rules of language teaching and student learning needs, a multi-level, multi-level curriculum system should be built, from English ability, academic English ability, working capacity in English, intercultural communication skills and other areas of the design of different levels of teaching objectives. 


\section{Reference}

[1] J.G. Cai. Research on the Orientation of College English Teaching under the Background of Educational Internationalization [J]. Foreign Languages, 2012, (01): 69-76.

[2] Y. Jiang. College English curriculum evaluation system construction [J]. Shandong Foreign Language Teaching, 2013, (05): 56-62.

[3] M. Li, J. G. Cai. The Reform of College English Teaching in the Transitional Period - An Interview with Professor Cai Jiigang [J]. Shandong Foreign Language Teaching, 2013, (05): 3-6.

[4] G.Q. Li. Attaches great importance to college English teaching reform efforts to improve the quality of college English teaching [J]. Foreign Language Teaching and Research, 2012, (02): 279-282.

[5] W.M. Zhang, W.X. Zhang, M.H. Liu. Construction and exploration of English education system in research university - Taking Tsinghua University as an example [J]. Modern Foreign Language, 2015, (01): 93-101,146-147.

[6] Ortega, L. Meaningful L2 practice in foreign language classrooms: A cognitive-interactionist SLA perspective [A]. In Dekeyser RM (Ed.). Practice in a Second Language: Perspective from Applied Linguistics and Cognitive Psychology [C]. Cambridge: Cambridge University Press, 2007:180-207. 